\title{
THE COAGULATION DEFECT IN HEMOPHILIA: A COMPARISON OF THE PROTEOLYTIC ACTIVITY OF CHLOROFORM PREPARATIONS OF HEMOPHILIC AND NORMAL HUMAN PLASMA 1, 2
}

\author{
By HENRY J. TAGNON, CHARLES S. DAVIDSON, AND F. H. L. TAYLOR \\ (From the Thorndike Memorial Laboratory, Second and Fourth Medical Services (Harvard), \\ Boston City Hospital, and The Department of Medicine, \\ Harvard Medical School, Boston)
}

(Received for publication September 9, 1942)

It has been shown that, following the treatment of normal, human, cell-free plasma with chloroform, a proteolytic enzyme is elaborated (1). It has also been shown that the enzyme is associated with the globulin fraction of the plasma proteins $(1,2)$. Furthermore, it has been demonstrated that the enzyme may be prepared by the action of chloroform on a saline solution of human plasma euglobulin (1). Because hemophilic blood is known to have a deficiency in the coagulation activity associated with plasma euglobulin $(3,4)$, it seemed advisable to compare hemophilic and normal human plasmas as sources of enzyme activity.

The present communication concerns a comparative study of the proteolytic activity of normal and hemophilic plasma after treatment with chloroform.

\section{EXPERIMENTAL}

Fifty ml. of blood were aspirated into a syringe containing $0.5 \mathrm{ml}$. of 20 per cent potassium oxalate. The plasma was removed by centrifuging at 2,500 r.p.m. It has previously been shown that removal of blood platelets had no effect on the potency of the plasma enzyme, but in some instances, the plasma was recentrifuged at 4,200 r.p.m. in an angle head centrifuge. This latter operation rendered the plasma essentially cell-free. Plasma was prepared from 7 normal individuals and 7 cases of hemophilia. In each experiment, one normal and one hemophilic plasma was handled simultaneously and treated

1 Presented in part before the American Society for Clinical Investigation, May 4, 1942, Atlantic City, New Jersey.

2 The expenses of this investigation were defrayed, in part, by a gift to Harvard University from the Smith, Kline \& French Laboratories, Philadelphia, Pennsylvania; and, in part, by a grant given "in recognition of Dr. Francis W. Peabody's services to the Foundation" by the Ella Sachs Plotz Foundation.

3 Graduate Fellow, Belgian American Educational Foundation (1942-1943). under exactly duplicate conditions. The patients were proven cases of hemophilia with a venous blood coagulation time, for $2 \mathrm{cc}$. of blood, greater than one hour which is about 6 times normal.

The plasma was transferred to $50 \mathrm{ml}$. glass bottles and $1 / 10$ the volume of chloroform added. The mixture was vigorously shaken for one minute and allowed to stand at room temperature until the clot which formed had undergone lysis. It should be noted that both the hemophilic and normal plasmas clotted after the addition of the chloroform in about the same time. In both instances, less than 16 hours were required. The time for complete dissolution of the clot was recorded. The data of the 7 experiments are given in Figure 1. It will be observed that in each instance it took much longer for the clot in the hemophilic plasma preparation to disappear than in the normal plasma preparation. However, there was no direct relation between the coagulation time of the hemophilic blood and the time required for dissolution of the clot. On the average, it took approximately twice as long for clot dissolution in the case of hemophilic plasma preparations as in the case of normal plasma preparations. It will be observed that the same results obtain whether the platelets had been removed from the plasma or not.

It has previously been shown $(1,5)$ that when human plasma is shaken with chloroform, a clot is formed. When this clot has entirely dissolved, the chloroform plasma preparation contains an active proteolytic enzyme. The activity of a given preparation can be readily measured by determining the rate of disappearance of a given quantity of fibrinogen. The disappearance of fibrinogen can be determined by the addition of an active thrombin solution to the fibrinogen solution. Accordingly, to a given quantity of fibrinogen in solution, $0.5 \mathrm{ml}$. of chloroform plasma preparation was added, and the time required for the complete disappearance of fibrinogen determined by the addition of thrombin. The time from the addition of the chloroform plasma to the time when no further fibrinogen remained was recorded. The temperature was held constant at $37.5^{\circ} \mathrm{C}$. In this way, the proteolytic activities of chloroform preparations of normal and hemophilic plasma were compared. The data are presented in Table I. It will be observed that the normal chloroform plasma preparations were much more active in the production of fibrinogenolysis than were the preparations from hemophilic plasma. Only hemophilic preparation 6 pro- 


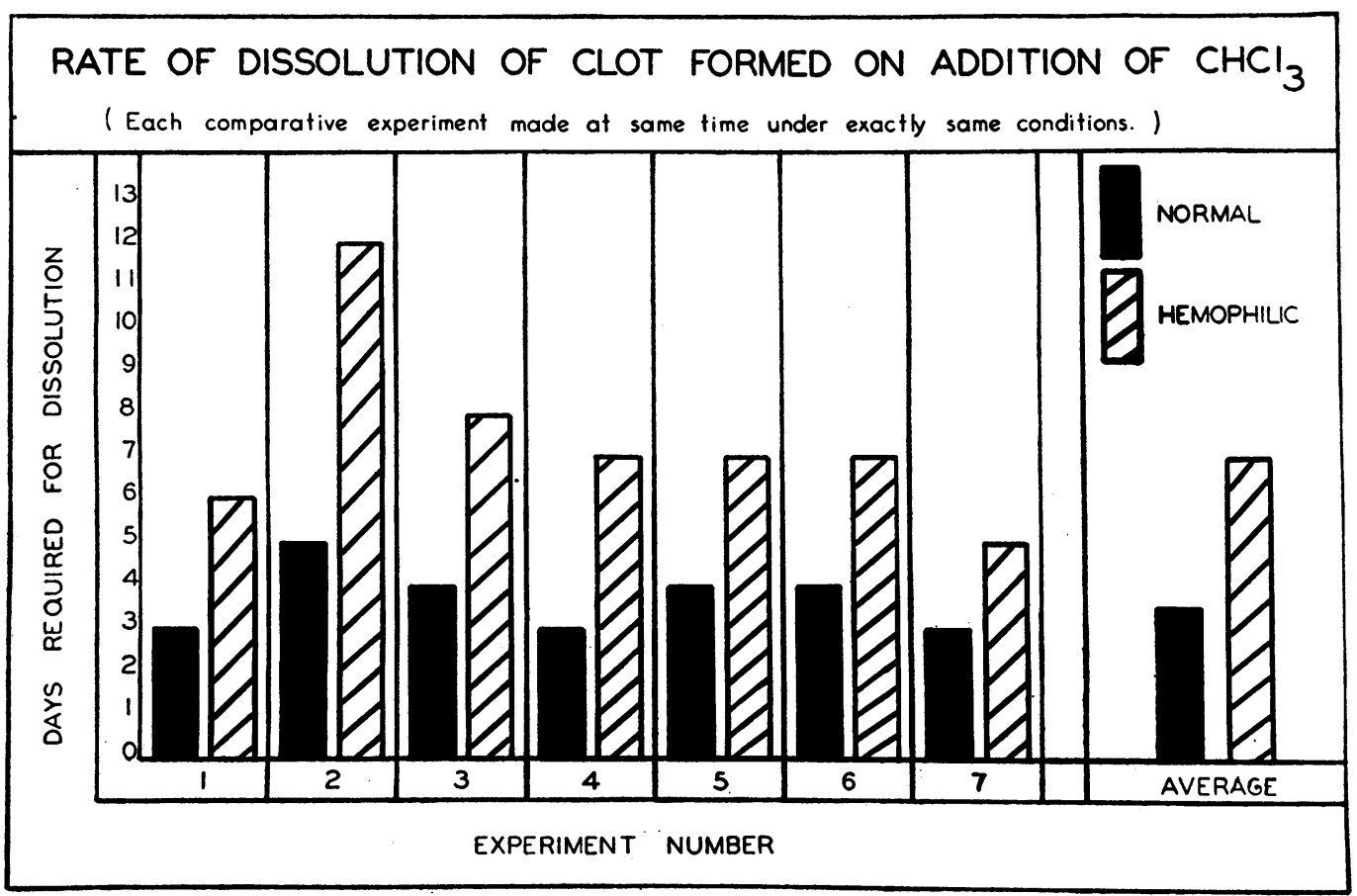

Fig. 1. Comparison of the Proteolytic Activity of Normal and Hemophilic Chloroform Plasma Preparations

Numbers 1 and 2 were platelet-free.

duced an activity in any way comparable to the proteolytic activity of normal plasma preparation. The rate of disappearance of the fibrinogen did not parallel the coagulation time of the hemophilic blood.

TABLE I

Comparison of the proteolytic activity of normal and hemophilic chloroform plasma preparations

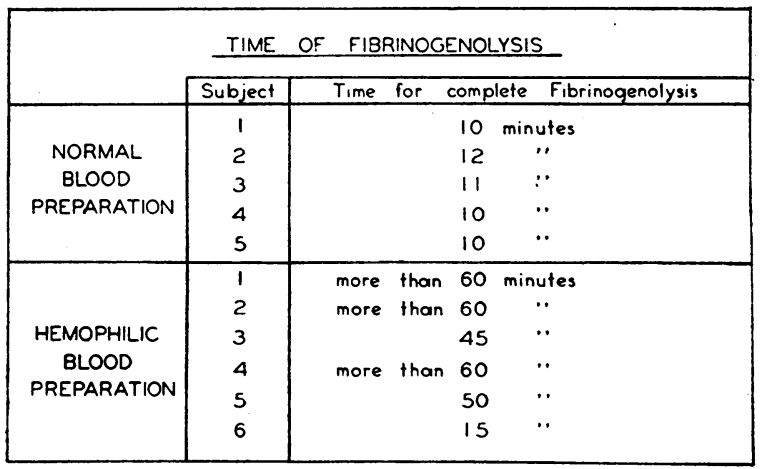

\section{DISCUSSION}

The biochemical lesion in hemophilic blood has been the subject of much study. It is generally accepted that prothrombin and fibrinogen appear to be normal in amount. So far as cell-free plasma is concerned, it appears that the only deficiency at present recognized lies in the clotting activity of the globulin fraction of the serum proteins (3), free from fibrinogen and prothrombin (4).

It has been shown that the addition of "globulin substance" to hemophilic blood, both in vivo and in vitro, results in a decrease of the blood coagulation time of hemophilic blood toward normal. "Globulin substance" is, however, far from a pure substance. The only chemically pure physiological substance having this coagulation effect is crystalline trypsin (6), the action of which has only been investigated in vitro.

The proteolytic enzyme prepared from calcium and cell-free human plasma described by Tagnon and his associates $(1,2,5)$ resembles trypsin in many ways. However, the plasma enzyme, unlike trypsin, is a plasma derivative and can be obtained from that portion of the plasma proteins having marked coagulation effect in hemophilia, both in vivo and in vitro. While the relation of the plasma enzyme to blood coagulation is not fully 
understood, its resemblance to trypsin as a proteolytic enzyme and its relation to known coagulation factors would indicate that it plays some important role in blood coagulation. The data presented in this paper offer still further evidence of its essential character in blood coagulation. On the basis of the evidence submitted in this communication, the activity of the plasma proteolytic enzyme is reduced in preparations of hemophilic plasma as compared to entirely similar preparations of normal human plasma. Whether this reduced activity is due to less enzyme being elaborated or to the presence of powerful inhibitor substances in hemophilic blood remains to be investigated.

\section{CONCLUSIONS}

1. The rate of dissolution of the clot obtained by the action of chloroform on hemophilic plasma is much slower than in the case of normal human plasma preparations.

2. The rate at which chloroform plasma preparations derived from normal human plasma can cause fibrinogenolysis is much greater than that of similar preparations from hemophilic plasma.

3 . It is concluded that the proteolytic activity of chloroform preparations of hemophilic plasma is less than for such preparations from normal human plasma.

\section{BIBLIOGRAPHY}

1. Tagnon, H. J., Davidson, C. S., and Taylor, F. H. L., Studies on blood coagulation: A proteolytic enzyme prepared from calcium and platelet free normal human blood plasma. J. Clin. Invest., 1942, 21, 525.

2. Tagnon, H. J., The significance of fibrinolysis in mechanism of coagulation of blood. J. Lab. and Clin. Med., 1942, 27, 1119.

3. Patek, A. J., Jr., and Taylor, F. H. L., Hemophilia. II. Some properties of a substance obtained from normal human plasma effective in accelerating the coagulation of hemophilic blood. J. Clin. Invest., 1937, 16, 113.

4. Lozner, E. L., Kark, R., and Taylor, F. H. L., The coagulation defect in hemophilia: The clot promoting activity in hemophilia of Berkefelded normal human plasma free from fibrinogen and prothrombin. J. Clin. Invest., 1939, 18, 603.

5. Kaplan, M. H., Tagnon, H. J., Davidson, C. S., and Taylor, F. H. L., Studies on blood coagulation: The nature and properties of a proteolytic enzyme derived from plasma. J. Clin. Invest., 1942, 21, 533.

6. Eagle, H., and Harris, T. N., Studies in blood coagulation. V. The coagulation of blood by proteolytic enzymes (trypsin, papain). J. Gen. Physiol., 1937, 20, 543 . 